\title{
Entre utopías y realidades: la Organización Mundial de la Salud y sus claves históricas, 1948-2018
}

\author{
Between utopias and realities: the World Health \\ Organization and its historical benchmarks, 1948-2018
}

\author{
Rosa Ballester-Añón ${ }^{i}$ \\ Catedrática emérita, Departamento de Salud Pública, Historia de la Ciencia y Ginecología/ \\ Facultad de Medicina/Universidad Miguel Hernández. \\ San Juan de Alicante - Alicante - España \\ orcid.org/0000-0002-7870-4185 \\ Rosa.Ballester@umh.es
}

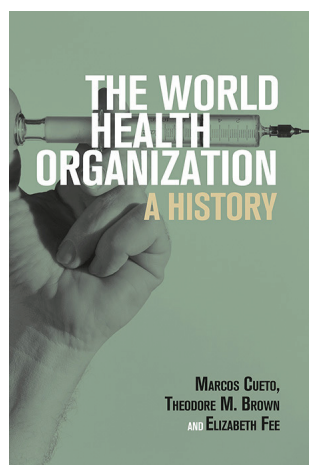

CUETO, Marcos; BROWN, Theodore M.; FEE, Elizabeth. The World Health Organization: a history. Cambridge: Cambridge University Press. 2019. 388p.

La obra es el resultado de la colaboración estrecha, a través de casi dos décadas, de tres historiadores importantes, de dilatada y fecunda trayectoria, que han confluido felizmente para realizar un trabajo de alta calidad y envergadura, hasta tal punto que constituye una referencia obligada no solo para el estudio del organismo sanitario stricto sensu sino, a lo largo de todo el periodo histórico que abarca de la salud internacional todas sus facetas y, aún más, de la historia, los cambios en las políticas de carácter global, como señala Randall Packard en la contraportada. Y una ausencia dolorosa: la de Elizabeth Fee, fallecida cuando la obra ya estaba completa, pero que ha dejado su impronta en la misma.

Políticos, gestores, diplomáticos, sanitarios, son actores privilegiados de esta historia. Una historia que los autores se encargan bien pronto de decir que no se trata de una historia oficial o semioficial, como las que abarcando los diferentes decenios de la Organización Mundial de la Salud se han ido publicando. El estudio se apoya en muy abundantes y muy bien escogidas fuentes primarias - muchas archivísticas e inéditas (una relación de las cuales se encuentra en p.341-351), incluyendo testimonios orales de personalidades tan emblemáticas cono Halfdan Mahler o Ilona Kickbusch.

Un análisis perfectamente contextualizado a través de la bibliografía secundaria permite reconstruir esta historia sobre la base inicial de trabajos de pioneros, presentes en el libro editado por Paul Weindling, como los de Iris Borowy, indispensables para entender los orígenes de instituciones anteriores a la OMS; la reciente obra de Randall M. Packard (2016) sobre historia de la salud global; los estudios del propio Marcos Cueto sobre la Paho; los sugerentes trabajos de Anne-Emanuelle Birn; los de Josep L. Barona (2018); la extensa y bien documentada biografía de John Farley (2008) sobre Brock Chisholm, y, desde luego, los trabajos previos de los tres autores de la monografía, entre otros. 
Una característica singular del texto es como el análisis subraya la complejidad de los elementos intervinientes en el desarrollo del organismo multilateral a lo largo de su historia, desde su fundación hasta la actualidad. En ese sentido, junto a una información factual muy detallada y ordenada cronológicamente, lo más importante es precisamente el interés de los autores por darnos las claves que nos permiten entender los cambios en una historia que no es de un progreso y éxito lineales, sino que está llena de altibajos, de logros importantes, pero también de algunos fracasos. Tras un capítulo introductorio, que nos sitúa perfectamente en los objetivos que se pretende alcanzar y nos resume los hitos principales de este relato, el volumen incluye 11 capítulos, cada uno de los cuales con diferentes epígrafes, muy útiles, para identificar los distintos problemas que se abordan. El primero, "The making of an international health establishment", un pórtico necesario para comprender lo que sucederá después, arranca de la primera conferencia sanitaria internacional (Paris, 1851) y de las diferentes actividades y entidades que surgieron posteriormente, muy en especial de la Organización de Higiene de la Sociedad de Naciones, el papel de la oficina de higiene de la Organización Panamericana de Salud, de la Fundación Rockefeller y de la Administración de las Naciones para el Socorro y la Reconstrucción (UNRRA).

El capítulo segundo, "The birth of the WHO, 1945-1948", enlaza con el anterior, subrayando continuidades y legados de las agencias creadas en el periodo anterior y los motivos por los que se considera poner en marcha esta agencia sanitaria especializada dentro de la Organización de las Naciones Unidas. La cristalización de la idea inicial en un conjunto de realidades en los años iniciales del proceso, lo encontramos en el tercer capítulo, "The start-up years, 1948-1953", marcado por los conflictos surgidos por la considerada excesiva preponderancia de los EEUU por parte de la URSS y sus aliados. Dos protagonistas destacados: Marcolino Candau y Brock Chisholm y su apoyo a que la nueva agencia creada fuera capaz de llevar a cabo sus funciones sin el excesivo peso de las dos superpotencias mundiales y en el contexto de la Guerra Fría. Precisamente, los capítulos siguientes "The Cold War and eradication" y "Overcoming the warning of the Cold War: smallpox eradication", plantean de frente, entre otras cosas, como el llevar a cabo programas con un mismo objetivo - la erradicación de enfermedades infecciosas - las respuestas y los resultados finales pueden ser diferentes dependiendo de que los enfoques sean de tipo horizontal (sociomédico) o vertical (biomédico, monofocal).

Dos de los capítulos más sugestivos son el sexto, "The transition from 'family planning' to 'sexual and reproductive rights'", y el séptimo, "The vicissitudes of the primary health", que transcurren en las décadas de los 1970 y 1980 y que nos remiten a un interesante periodo en el que se plantean desde aspectos relativos al control poblacional a cuestiones conceptuales como la definición de atención primaria de salud, a los inicios del programa "Salud para todos en el año 2000". Los orígenes de un nuevo enfoque social y la influencia de una nueva atmósfera donde obras como la de Thomas McKeown o Ivan Illich y actividades como la incorporación, en ciertos entornos, de las parteras tradicionales y los médicos descalzos en China son muy interesantes, así como la deriva posterior en un enfoque menos holístico. 
"The response to the HIV/Aids pandemic" (capítulo ocho) y las respuestas de la OMS, de gran repercusión social, a este nuevo problema es seguido por el capítulo nueve, "An embattled Director-General and the persistence of the WHO", un sugestivo análisis - desde sus componentes político-estratégicos y también desde la propia figura del director general - de un periodo, en la década de los 1990, de crisis profunda de la propia institución. Precisamente, también en esta década, asistimos al preámbulo de la situación actual. De ese modo, "The competitive world of global health" (capítulo diez) es un abordaje muy clarificador de cómo el impacto de la globalización, en el más amplio sentido, ha permeado las actividades y los propios planeamientos programáticos de la OMS. Para finalizar, lo más actual, "The World Health Organization in the second decade of the twenty-first century" (capítulo 11), un repaso por las respuestas a la epidemia de Ébola y sobre todo, los nuevos retos con la intervención de organizaciones - públicas y sobre todo privadas - nuevas en temas sanitarios internacionales. Nuevos retos que exigen nuevas respuestas y nuevos análisis a los que el libro que comentamos tiene tanto que ofrecer desde una visión crítica pero apasionada y positiva, de una institución ya con larga vida, pero siempre renovada.

Subrayaría dos de los ejes centrales de esta historia, aunque la auténtica protagonista es la población y su derecho a la salud. Por un lado, el estilo y las perspectivas de los sucesivos directores generales, desde el canadiense George Brock Chislhom al etíope Tedros Adhanom Ghebreyesus, que son analizados por los autores del libro sin afán hagiográfico y, en algún caso, con un importante sentido crítico. En segundo término, un hilo conductor, la existencia, a lo largo de los 70 años de la Organización, de dos tipos de enfoques: por un lado, los médico-sociales y, frente a ellos, los tecnocráticos, medicalizados y con fuerte influencia de determinados países y de políticas liberales y neoliberales.

En suma, una excelente e indispensable historia actualizada de la Organización Mundial de la Salud que, como sucede con los buenos trabajos, es el acicate perfecto para plantearse a desarrollar, a partir de ahí y en este magnífico contexto global nuevas preguntas y nuevas respuestas. Por ejemplo, ahondar en el devenir de las oficinas regionales de la Organización menos estudiadas (un modelo son los importantes trabajos de Sanjoy Bhattacharya, citados en el texto) y, aún más, incidir en la especial relación del organismo internacional con países concretos, con regímenes políticos diferentes y cambiantes (como, y es un ejemplo concreto, el caso de las dictaduras de España y Portugal) y la influencia en dicho devenir, de las becas y viajes de estudio, de los informes de consultores y expertos independientes enviados con el objeto de analizar políticas sanitarias globales (RodríguezOcaña, Ballester-Añón, 2019) o aspectos particulares relativos al funcionamiento real, en un determinado país, de programas de vacunación o de control de enfermedades como la fiebre de Malta o la malaria. Estos trabajos de campo, estas miradas externas, locales, constituyen otros tantos aspectos complementarios y parte de la historia de la Organización Mundial de la Salud. 


\section{REFERENCIAS}

BARONA, Josep L.

Health policies in interwar Europe: a transnational perspective. London: Routledge. 2018.

CUETO, Marcos; BROWN, Theodore; FEE, Elizabeth.

The World Health Organization: a history.

Cambridge: Cambridge University Press. 2019.

FARLEY, John.

Brock Chisholm, the World Health Organization, and the Cold War. Vancouver: University of British Columbia Press. 2008.
PACKARD, Randall M.

A history of global health: interventions into the lives of other peoples. Baltimore: Johns Hopkins University Press. 2016.

RODRÍGUEZ OCAÑA, Esteban; BALLESTERAÑóN, Rosa.

El informe del consultor de la OMS Fraser Brockington de 1967, en el contexto del reformismo sanitario franquista. Dynamis, v.39, n.2, p.477-496. 2019. 